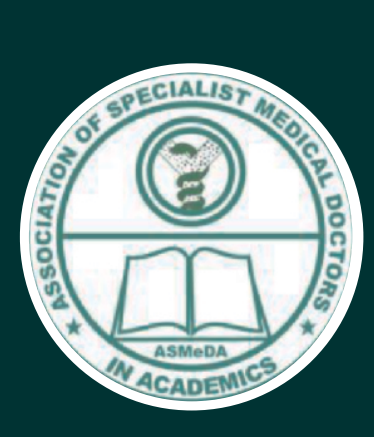

ISSN:Print: 2811-1672

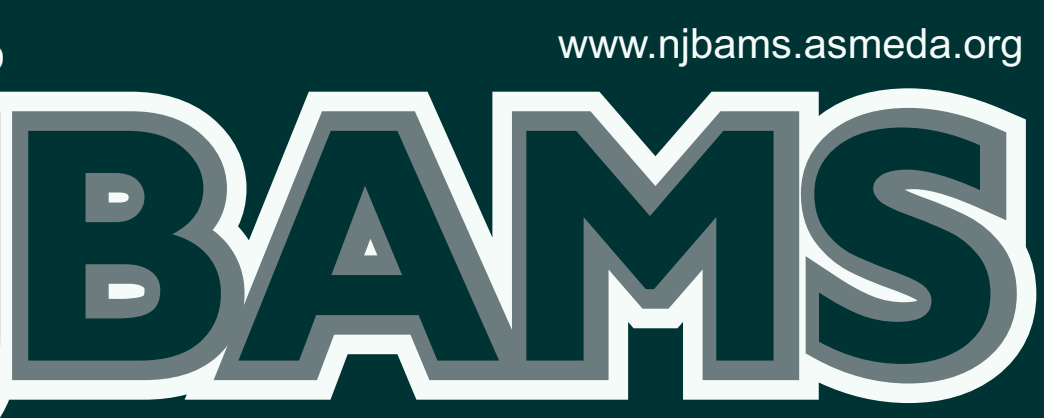

Nigerian Journal of Basic and Applied Medical Sciences

An official publication of the National

ASSOCIATION OF SPECIALIST MEDICAL DOCTORS IN

ACADEMICS (ASMeDA aka MEDSABAMS) 


\title{
Evaluation of Memory Impairment Following Prenatal Exposure to Mosquito Coil Smoke
}

\author{
Shehu K ${ }^{1}$, Badamosi I.M. ${ }^{2}$, Saleh M.S. ${ }^{2}$ \\ ${ }^{1}$ Department of Anatomy, College of Health Sciences, Federal University, Birnin-Kebbi \\ 'Department of Anatomy, Faculty of Basic Medical Sciences, Bayero University Kano
}

\begin{abstract}
Background: Developmental Neurotoxicity can lead to the buildup of reactive oxygen species which is an indicator to oxidative stress in the prenatally exposed offspring. Neuronal oxidative stress induces neuroinflammation, precedes tangle formation, and disrupts synaptic plasticity. The result of such changes may be expressed into adulthood as behavioral deficits. All together, these mechanisms are implicated in memory disorders.

Objectives: To investigate the histochemical changes in the hippocampus and entorhinal cortex of Wistar rats' offspring after prenatal exposure to mosquito coil smoke and its effect on memory. .

Methods: 12 pregnant Wistar rats were grouped into four, 3 animals per group. Group I was exposed to fresh air. Groups II, III, and IV were exposed to mosquito coil smoke for 4,6 and 8 hours daily respectively throughout gestation period. On Post-natal day (PND) 28 and 29, shortterm spatial and recognition memory of adolescent wistar rats were assessed using water licking task and novel object recognition test respectively.
\end{abstract}

\section{INTRODUCTION}

Memory is an organism's ability to encode, retain and retrieve information and experience (1). The entorhinal cortex is situated in the medial temporal lobe and its normal structure and function is crucial for familiarity-based recognition (2). It has been reported that the entorhinal cortex is susceptible to the deleterious effects of intoxicants (3). The hippocampus is an important structure of the medial temporal lobe, and its structural integrity is crucial for normal acquisition of spatial and relational processes $(2,4)$.

The use of mosquito coils as an insecticide in the control of mosquito has increased in recent years (5). Mosquito coil contains pyrethroids as active constituents, and it has been reported that pyrethroids caused a dose-dependent reduction in hippocampal cells responsiveness (5). Increased gestational exposures to pyrethroids have raised concerns over their potentials as developmental neurotoxicants, and their effects at some instances are expressed into adulthood as cognitive impairments $(6,7)$. The mechanism of pyrethroids neurotoxicity and their ability to cross the blood-brainbarrier has been reported $(7,8)$.

The developing brain contains low antioxidant defense and thence, is more susceptible to oxidative insults from exposure to neurotoxins, leading to oxidative stress (8). Oxidative stress, indicated by the buildup of reactive oxygen species $(8,7)$ is considered a critical pointer to oxidative damage (9). Damage to a particular structure or to a connecting pathway in the developing nervous system can produce structural or functional changes $(3,10,11)$. Moreover, Neuronal oxidative stress precedes tangle formation (12), induces neuroinflammation and disrupts synaptic plasticity (13). These mechanisms are all implicated in memory disorders (14).

Cite this article as: Shehu K., Badamasi I.M., Saleh M.S. Evaluation of Memory Impairment Following Prenatal Exposure to Mosquito Coil Smoke. Nig. J. Basic \& Applied Med. Sci. 2021;1(1);10-13.
For each animal group (I-IV), a total of 8 animals were randomly selected from the litters for neurobehavioral studies. Experimental animals were humanely sacrificed and sections from the hippocampus and entorhinal cortex were processed for histochemical studies using Bielschowsky stain. Data were presented as mean \pm SEM; analysed using One-way analysis of variance and Tukey's Multiple Comparison Test $(p<0.05)$.

Results and Conclusion: Our results showed significant impairment in short-term recognition and spatial memory of group III and IV adolescent wistar rats when compared with the control $(\mathrm{p}<0.05)$ and the formation of neurofibrillary tangle-like structures in neurons of the studied regions. .

Keywords: Memory, Hippocampus, Mosquito coil smoke.

\section{Corresponding Author:}

Name: Saleh MS,

Address: Department of Anatomy, Faculty of Basic Medical Sciences,

Bayero University Kano, Nigeria.

Email: sagirsaleh007@gmail.com.

Phone: 08023098344.
Despite its health implications, mosquito coils are still being used by households to control mosquitoes in Nigeria. Previous studies have focused more on the effects of prenatal exposure to mosquito coil smoke (MCS) on structures of the reproductive, urinary and respiratory systems. Studies on the developmental neurotoxicity of MCS are scanty.

This study will investigate the effects of prenatal exposure to MCS on the histomorphology of two important memory structures; the hippocampus and entorhinal cortex, and its effect on memory.

\section{METHODOLOGY}

\section{Ethical Clearance}

Approval for this study was obtained from the research ethical committee of Anatomy Department, Faculty of Basic Medical Sciences, Bayero University Kano.

\section{Materials}

Mosquito coil (Brand Name: WAVETIDE, Active Ingredient: 0.05\% Meperfluthrin, Pesticide Registration Number: WP20140093, Production Certificate Number: HNP 33099-I2694), partially ventilated chamber $(2.00 \times 0.98 \times 1.55 \mathrm{~m})$, Wistar rats $(20$ females, 10 male), Animal feed (Olam feeds), Light Microscope (Nikon E600 microscope, U.S.A), Digital AmScope (MD 900, Japan), Neurobehavioural test apparatus.

\section{METHODOLOGY}

\section{Exposure to Mosquito Coil Smoke}

12 pregnant rats were randomly grouped into four, 3 animals per group and then transferred into separate unit cages. Animal groups in their respective cages were placed in a partially ventilated chamber $(2.00 \times 0.98 \times 1.55 \mathrm{~m}$ in dimensions) and a window cuts on two sides of the exposure chamber were made to allow for ventilation (5). For each of the groups, one mosquito coil was weighed, and the required gram was lit and placed in the exposure chamber. 
Table 1. Grouping of Pregnant Animals

\begin{tabular}{|c|c|}
\hline Group & Dose \\
\hline Group 1 & Control group exposed to room air throughout gestation. \\
\hline Group 2 & $\begin{array}{l}\text { Animals were exposed to mosquito coil smoke for } 4 \text { hours daily ( } 6 \text { grams of burning } \\
\text { mosquito coil) throughout gestation. }\end{array}$ \\
\hline Group 3 & $\begin{array}{l}\text { Animals were exposed to mosquito coil smoke for } 6 \text { hours daily }(9 \text { grams of burning } \\
\text { mosquito coil) throughout gestation. }\end{array}$ \\
\hline Group 4 & $\begin{array}{l}\text { Animals were exposed to mosquito coil smoke for 8hours daily (12grams of burning } \\
\text { mosquito coil) throughout gestation. }\end{array}$ \\
\hline
\end{tabular}

\section{Assessment of Short-Term Memory Function}

\section{Water licking task}

On post natal day (PND) 28, Short-term spatial memory was tested using the water licking task which is a modified version of the open field test (15).

The animal was deprived of water for a 24-hour period prior to the experiment. During the training session (T1), animals explore the new environment and locate the position of a water spout. An intertrial time of 15 minutes was allowed after which the animal was returned to the environment for same experiment in the test session (T2). The latency to find the spout and lick the water in T2 was recorded.

\section{Novel object recognition (NOR) test.}

On PND 29, Short-term recognition memory was tested using the novel object recognition (NOR) test as previously outlined (16). In the first phase of the experiment (T1), the animal was presented with two identical objects (blue) for 3 minutes after which an interval of 15 minutes (I.T) was allowed. For the second phase (T2), one of the presented objects was changed with a new object (red) for the test session ( 3 minutes). The time spent by the animal to explore the familiar and new objects was measured separately in T2 to determine the discrimination index (d2). Discrimination Index (d2) is taken by subtracting familiar object exploration time from that spent with new object. This is then divided by total exploration time. (i.e B A / e, where $\mathrm{B}=$ time spent with novel object, $\mathrm{A}=$ time spent with familiar object, and $\mathbf{e}=$ total exploration time, which was 3 minutes in this experiment). Decreased in $\mathrm{d} 2$ indicates an impairment in recognition memory (15).

\section{Animal Sacrifice}

On PND 30, the animals were anaesthetized using $10 \mathrm{mg} / \mathrm{Kg}$ ketamine. Subsequently, the animals were perfused (transcardial) through the left ventricle with $10 \%$ Formalin. Subsequently, the skull was opened to harvest the whole brain following which it was fixed in the perfusion fixative.

\section{Tissue Processing}

After fixation, sections of 5 um thickness were taken through the hippocampus and entorhinal cortex. The tissues were processed and paraffin wax embedded tissues blocks were prepared. Sections were taken and subsequently processed for routine $\mathrm{H} \& \mathrm{E}$ and Bielschowsky special stain. Tissues were then mounted with cover slips using a mounting media. Sections of the tissues were viewed under light microscope and photomicrographs were taken.

\section{Statistical Analysis}

The results were analyzed using the GraphPad Prism Software version 5.01, and the results expressed as mean \pm SEM. Statistical significance between means were analyzed using one-way analysis of variance (ANOVA) and Turkey's Multiple Comparison Test. A p-value $<0.05$ was considered statistically significant.

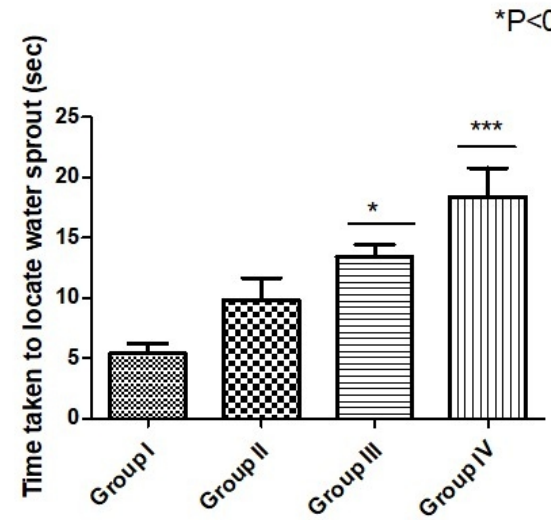

Figure 1. The Effect of Prenatal Exposure to MCS on Short-Term Spatial Memory of Adolescent Wistar Rats Evaluated Using the Water Licking Test.

${ }^{*} \mathrm{P}<0.05 ;{ }^{* * *} \mathrm{P}<0.001$

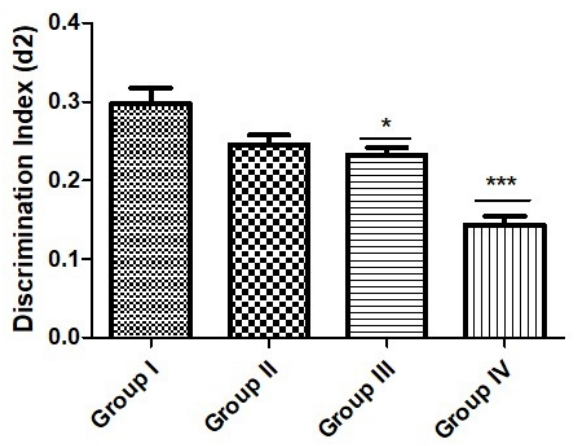

Figure 2: The Effect of Prenatal Exposure to MCS on Short-Term Recognition Memory of Adolescent Wistar Rats Evaluated Using the Novel Object Recognition Test.

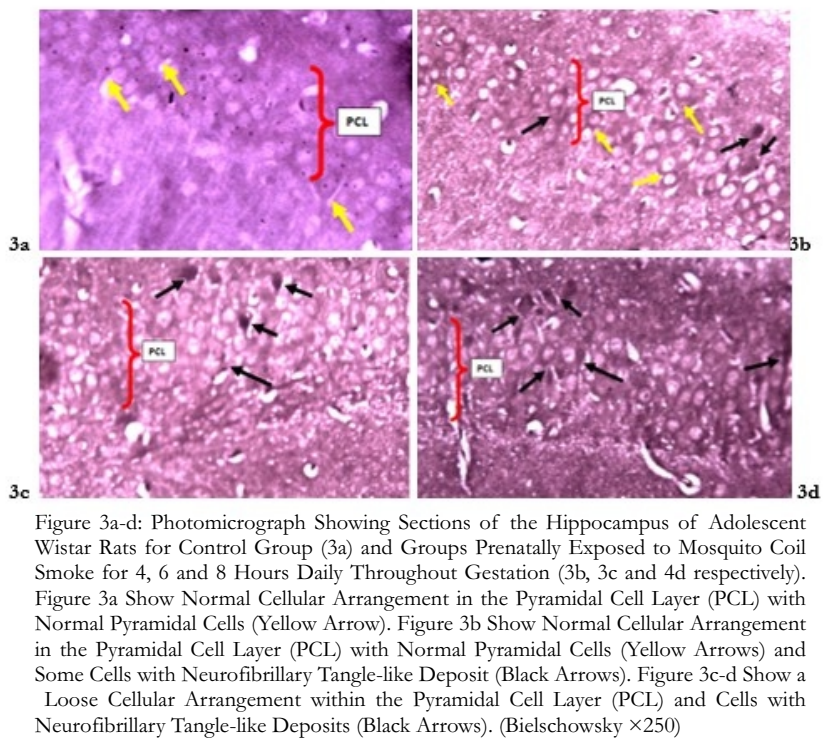

\section{DISCUSSION}

This study was designed to investigate the histochemical changes on the hippocampus and entorhinal cortex of Wistar rats' offspring after daily prenatal exposure to mosquito coil smoke (MCS), and its effect on memory. Using the water licking task test, daily prenatal exposure to mosquito coil smoke (MCS) showed a significant increase in latency implying a highly significant decrease 


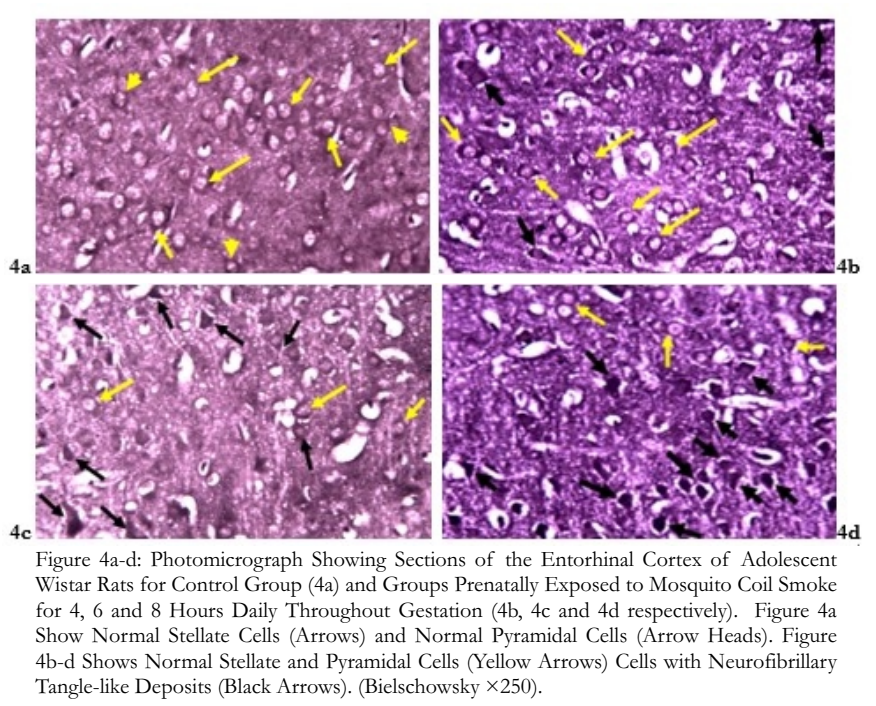

in short-term spatial learning and memory for group III $(\mathrm{p}<0.05)$ and group IV $(\mathrm{p}<0.001)$ when compared with the control group (Figure 1). This is in line with earlier work that reported a decrease in learning in mice exposed to MCS for few hours daily for three and six weeks as evaluated using the elevated plus maze (5,7). In another study involving exposure of rats to MCS daily for 1 to 3 hours, a non-significant increase in latency was observed when evaluated using Morris water maze test (10). The difference between this study and that reported in the literature (10) may be due to the difference in duration of exposure. The decrease in spatial memory as observed in this study could be attributed to the distortion of the normal cellular arrangement in the pyramidal cell layer of the hippocampus (Figure 3c-3d) and the formation of neurofibrillary tangle-like deposits within the cells of the hippocampus (Figure 3b-3d). Also, a previous study has shown that pyrethroids caused a dose dependent change in the responses of hippocampal cells (5) and these cells are critical in learning and memorizing spatial navigation (18). This effect of pyrethroids on the activity of hippocampal neurons may have as well contributed to the decrease in spatial memory observed in this study since mosquito coil contains pyrethroids as active ingredients.

In this study, a significantly lower discrimination index score for groups III $(\mathrm{p}<0.05)$ and group IV $(\mathrm{p}<0.001)$ was observed when compared to group I (control) (Figure 2). This implies that a decrease in short-term recognition memory was obtained following prenatal exposure to MCS for 6 and 8 hours daily. These findings agree with a recent study which observed a decrease in short-term memory of rats exposed to MCS for 1 to 3 hours daily for 28 days as evaluated using novel object recognition test (10).

The structural and functional integrity of the entorhinal cortex is crucial for familiarity-based recognition (2). It has been reported that the entorhinal cortex is susceptible to the deleterious effects of intoxicants (3). Our present study has shown that prenatal exposure to MCS affects the normal cytoarchitecture of the entorhinal cortex in exposed offspring (Figure 4b-d). These changes within the entorhinal cortex may be responsible for the impaired recognition memory observed in the MCS exposed groups (II-IV).

Mosquito coil smoke contain many gases and particles like carbon monoxide (CO), carbon dioxide (CO2), Pyro(a)benzene and other hydrocarbon(20). CO is known for its ability to supplant hemoglobin of its oxygen and thereby, exposing the neuronal cells to hypoxic state (21). This may result in arrest of cellular functions and lead to cellular death (20). Mosquito coil smoke also releases gases and particles that could interfere with the normal cellular processes of energy generation (22). One of the first results of energy depletion may involve the failure of $\mathrm{Na}+$ and $\mathrm{K}+$ pumps with associated depolarized state of the neuron membrane. This is further associated with failure of synaptic function and conductivity (23). Glutamate is released into the synaptic cleft as a result of neuronal depolarization leading to the excitation of neurons. But when the glutamate is in excess, it becomes an excitotoxin (23). Since some glutamate receptors are non-selective cation-permeable ion channels, over activation of these channels causes a passive influx of $\mathrm{Cl}$ - and $\mathrm{Na}+$ into cells causing cytotoxic oedema and rapid cell death (23). Additional structural damage develops hours or days as a result of $\mathrm{Ca}+$ influx into neurons (23).

Findings from this study also show that prenatal exposure to MCS can lead to the formation of neurofibrillary tangle (NTF)-like deposits in the cells of the hippocampus and entorhinal cortex. This could possibly be through mechanisms previously reported $(5,10,24)$.

It was suggested that MCS exposure mediates its neurotoxicity through depletion of important trace elements which subsequently leads to oxidative damage. Oxidative damage is a prerequisite to NFT formation $(10,12,13)$. Neuronal oxidative stress precedes NTF formation (12), induces neuroinflammation and disrupts synaptic plasticity (13). These mechanisms are all implicated in memory disorders (14).

\section{CONCLUSION}

Prenatal exposure to mosquito coil smoke causes alteration in the histomorphology of the hippocampus and entorhinal cortex, and impairment in short-term recognition and spatial memory of prenatally exposed adolescent Wistar rats.

\section{CONFLICT OF INTEREST}

None declared.

\section{REFERENCES}

1. Michael EH. A model of episodic memory: Mental time travel along encoded trajectories using grid cells. Neurobiol. Learn. Mem. 2009 ; 92(4) : 559-573.

2. Buzsaki G, Moser EI. Memory navigation and theta rhythm in the hippocampalentorhinal system. Nat. Neurosci. 2013; $16: 130138$

3. Ibrahim KR, Hala ZE. Histological changes of the adult albino rats' entorhinal cortex under the effect of tramadol administration: Histological and Morpho metric study. Alexandria J. Med. $2016 ; 53: 123133$.

4. Hafting T, Fyhn M, Molden S, Moser MB, Moser EI. Microstructure of a spatial map in the entorhinal cortex. Nature. $2005 ; 436: 801806$

5. Mshelia PP, Magaji RA, Dikko AU. Cognitive Effect of Sub-Acute Exposure to Mosquito Coil Smoke in Mice. J Pharm Bioll Sci. 2013 ; 8(2) : 26-30.

6. Dewailly E, Forde M, Robertson 1, Kaddar N, Laouan S, Cote S, Gaudreau E, Ayotte P. Evaluation of pyrethroid exposures in pregnant women from 10 Caribbean countries. Environ Intern. 2014 ; 63 : 201-206.

7. Sinha C, Seth PK, Islam F, Chaturvedi RK, Shukla S, Mathur N, Srivastava N, Agrawal AK. Behavioral and neurochemical effects induced by pyrethroidbased mosquito repellent exposure in rat offsprings during prenatal and early postnatal period. NeurotoxicolTeratol. $2006 ; 88: 472481$

8. Sinha C, Agrawal AK, Islam F, Seth K, Chaturvedi RK, Shukla S, Seth PK. Mosquito repellent (pyrethroid-based) induced dysfunction of bloodbrain barrier permeability in developing brain. Int. J. Dev. Neurosci. 2004 ; 22 : 3137

9. Syed F, John P, Inderpal S. Neurodevelopmental Consequences of Gestational and Lactational Exposure to Pyrethroids in Rats. Environ. Toxicol. 2015 ; 12 : 1761- 1770

10. Mahmood U, Adebayo B, Ahmed SI, Abubakar SA, Muhammad MM, Haruna DU. Effect of Exposure to Mosquito Coil Smoke on Short-Term Memory of Adult Wistar Rats. Nig. J. Neurosci. 2018 ; 9(1) : 24-28

11. Imanishi S, Okura M, Zaha H, Yamamoto T, Nagano R, Shiraishi H, Sone H. 
Prenatal exposure to permethrin influences vascular development of fetal brain and adult behavior in mice offspring. Environ Toxicol. 2013 ; 28(11) : 617- 629

12. Akihiko N, George P, Miguel A, Pappolla MA, Robert P, Keisuke H. Neuronal Oxidative Stress Precedes Amyloid-b Deposition in Down Syndrome. J. Neuropath. Exp. Neurol. $2000 ; 59(11)$ : 1011-1017

13. Gong Q, Su Y-A, Wu C, Si T-M, Deussing JM, Schmidt MV et al. Chronic Stress Reduces Nectin-1 mRNA Levels and Disrupts Dendritic Spine Plasticity in the Adult Mouse Perirhinal Cortex. Front. Cell. Neurosci. 2018 ; $12: 67-77$.

14. Pappolla MA, Omar RA, Kim KS, Robakis NK. Immunohistochemical evidence of oxidative stress in Alzheimer's disease. Am. J. Pathol. $1992 ; 140$ : 62128

15. Hamid HY, Zakaria A. Reproductive characteristics of the female laboratory rat; A Review. Academic Journals. 2012 ; 2(19) : 2510-2514

16. Quillfeldt JA. Behavioral Methods to Study Learning and Memory in Rats. Neurobiol. Learn. Mem. 2006 ; 66(2) : 97-101

17. Lueptow LM. Novel Object Recognition Test for the Investigation of Learning and Memory in Mice. J. Vis. Exp. 2017 ; $126: 45-48$

18. Andleeb S. Teratogenic potential of pyrethroids: a review Punjab Univ. J. Zool. 2016; 31(1) : 107-125

19. Abdel-Rahman A, Shetty AK, Abou-Donia MB. Subchronic dermal application of NN-diethyl m-toluamide (DEET) and permethrin to adult rats alone or in combination causes diffuse neuronal cell death and cytoskeletal abnormalities in the cerebral cortex and the hippocampus and Purkinje neuron loss in the cerebellum. Experimental Neurology. $2001 ; 172$ : 153171

20. Abubakar M, Hassan L. Toxicological Effects of Some Mosquito Coils Brands in Experimental Rats. The Internet Journal of Toxicology. 2006 ; 4(1) : 45-49

21. John K, Bryan H, Amanda F, Jeffrey KW, Maureen YL, William BH, David K Analysis of Pesticides and Toxic Heavy Metals Contained in Mosquito Coils. Bull Environ Contam Toxicol. 2016 ; 97 : 614-618

22 .Liu W, Zhang J, Hashim JH, Jalaludin J, Hashim Z, Goldstein BD. Mosquito Coil Emissions and Health. Implications Emviron Health Perspect. 2003; 111(12): 14541460

23. Dimitri P, Agamanolis MD. HypoxicIschemic Encephalopathy. Neuropathology. $2013 ; 8: 26-38$

24. Tina S, Lisbeth BM, Torben M. Impairment of Interrelated Iron and Copper Homeostatic Mechanisms in Brain Contributes to the Pathogenesis of Neurodegenerative Disorders. Front. Pharmacol. 2012 ; 3 : 169-181

25. Hardy J. Amyloid the presenilins and Alzheimer's disease. Trends Neurosci. $1997 ; 20: 15459$ 